\title{
Cardiovascular Risk Factors in Haul Truck Operators of the Mining Sector Working a Rotational Schedule
}

Rafaela Aparecida Mendonça Marques, ${ }^{\circledR}$ Priscila Pena Camargo, ${ }^{2}{ }^{\circledR}$ Gabriela Guerra Leal Souza, ${ }^{\circledR}$ Graziela Dutra Rocha Gouvea, ${ }^{\circledR}$ Virgínia Capistrano Fajardo, ${ }^{\circledR \oplus}$ Raimundo Marques do Nascimento Neto, ${ }^{1 \oplus}$ André Luis Silva, ${ }^{\circledR}$ Fernando Luiz Pereira de Oliveira ${ }^{\circledR}$

Universidade Federal de Ouro Preto, ' Ouro Preto, MG - Brazil

Secretaria Municipal de Educação de Ouro Preto, ${ }^{2}$ Ouro Preto, MG - Brazil

Universidade Federal de Minas Gerais, ${ }^{3}$ Belo Horizonte, MG - Brazil.

\section{Abstract}

Background: Due to the growing concern about work-related social and health aspects, occupational health and safety has become relevant.

Objective: This work aims to develop a model to assist cardiovascular risk management in a team of haul truck operators, who work in rotating shifts at a mining company in Brazil.

Methods: This longitudinal study evaluated risk factors for cardiovascular diseases of 191 mineworkers at three times points - 2010, 2012, and 2015. In addition, the risk of developing cardiovascular diseases was calculated, and the risk factors were analyzed using the chi-square test, the U Mann-Whitney test, and binary logistic regression. The significance level was set at $5 \%$.

Results: In the study period, body weight, body mass index (BMI), waist-to-height ratio (WHR), systolic (SBP), and diastolic blood pressure (DBP), total cholesterol, high-density lipoprotein cholesterol (HDL-C), and triglycerides levels of the study group increased. In 2015, there was a high prevalence of alcohol intake, overweight or obesity, central obesity, inadequate WHR, high blood pressure, total cholesterol above $190 \mathrm{mg} / \mathrm{dL}$, and triglycerides above $150 \mathrm{mg} / \mathrm{dL}$. An association was identified between increased cardiovascular risk and age, SBP, HDL-C, low-density lipoprotein cholesterol (LDL-C), and elevated glucose levels.

Conclusion: Intense interventions for reduction and prevention of elevated alcohol intake, blood pressure levels, WHR, metabolic syndrome, blood glucose, and LDL-C levels, and low HDL-C levels are needed. In addition, a close monitoring of mine workers over 38 years of age who smoke, consume alcoholic beverages, and have altered blood glucose levels is important.

Keywords: Cardiovascular Diseases, Risk Factors, Mineworkers; Shift Work Schedule; Occupational Health; Metabolic Syndrome; Alcoholism; Tobacco.

\section{Introduction}

According to the World Health Organization (WHO), cardiovascular diseases (CVD) are the leading cause of death worldwide, with more than three-quarters of these deaths occurring in low- and middle-income countries. ${ }^{1}$ Inappropriate lifestyle may be associated with increased risk and prevalence of cardiovascular diseases. ${ }^{2} \mathrm{~A}$ recent survey indicated that about 70\% of CVD and deaths in high and low-income countries, including Brazil, were attributable to modifiable risk factors. ${ }^{3}$ Therefore, preventative action is necessary to reduce or eliminate these factors, and consequently reduce the risk of developing CVD.

Mining industries have a significant contribution to the economy of Brazil, accounting for approximately

Mailing Address: Fernando Luiz Pereira de Oliveira

Institute of Exact and Biological Sciences, Universidade Federal de Ouro Preto

Ouro Preto - MG - Brazil

E-mail: fernandoluiz@ufop.edu.br 
2.6\% and the total Gross Domestic Product (GDP) and $14.4 \%$ of the industrial GDP in 2019. ${ }^{4}$ This sector exported about US\$29.9 billion and was responsible for generating 180 thousand direct jobs and two million indirect jobs in 2018. ${ }^{5}$ Mineworkers may be exposed to several CVD risk factors, such as high work stress, long working hours, ${ }^{6,7}$ and shift work. ${ }^{8,9}$ Therefore, further studies on the prevention of CVD among these workers are needed.

Occupational Health and Safety (OHS) is an important field, but a recent literature review ${ }^{10}$ showed that studies on OHS management have focused on work safety issues rather than health issues, and highlighted that a more effective OHS epidemiological management is needed. ${ }^{10}$ Although prevention in young people and individuals at low or moderate risk is still limited, it can provide important results. ${ }^{11}$

The present work aims to develop a model for CVD risk management assistance to be applied to a team of haul truck operators that works in rotating shifts at a mining company located in Minas Gerais, Brazil. For this, a longitudinal study was conducted, with 191 workers who were followed in three periods (2010, 2012, and 2015). The workers' risk factors for CVD were identified and analyzed, and their risk of developing CVD was calculated.

In addition, in face of the new coronavirus (COVID-19) pandemic, we believe this study will provide an important contribution to public health, due to associations of COVID-19 complications with CVD ${ }^{12,13}$ and some of its risk factors, such as hypertension, diabetes, ${ }^{14,15}$ smoking, ${ }^{15}$ and obesity. ${ }^{16}$

\section{Methods}

A longitudinal study was conducted in mining companies in the region of Inconfidentes, in Minas Gerais state, Brazil, and was divided into three phases: 2010, 2012 and 2015. Due to losses for various reasons (holidays, leaves, layoffs, etc.), in the evaluation carried out in 2015, a sample of 191 workers with complete data (2010, 2012 and 2015) was obtained. Then, only individuals who participated in these 3 periods were selected, which characterized an exclusion factor of other workers in previous moments. Therefore, data from the same 191 mining haul truck operators, who worked rotating shifts, were evaluated in all three phases of the study. There were no interventions on cardiovascular risk during the follow-up.

Work shifts consisted of a six-hour shift followed by a 12 hour-rest, based on a rotating shift schedule, as follows: a night shift from 7:00 pm to 1:00 am, an afternoon shift from 1:00 pm to 7:00 pm, a morning shift from 7:00 am to 1:00 pm, ending with a night/early morning shift from 1:00 am to 7:00 am. Fours shifts made a complete work cycle, after which the workers had a 36-hour rest period. Then, the worker returned to work the day after the break, from 7:00 pm to 1:00 am, restarting another work cycle.

For data collection, this research project was submitted and approved by the Research Ethics Committee of Universidade Federal de Ouro Preto (CAAE: 0018.0.238.000-11 and CAAE: 39682014.7.0000.5150, under approval number 1.381.376), and all volunteers signed an informed consent form. The dataset used in this study is available under request.

\section{Variables}

Sociodemographic variables - educational attainment (finished or some elementary school; high school; technical level; or higher education), marital status (married; not married; or separated), age (median), race (white; yellow; black; mulatto; and mestizo) and time of shift work (< five years; $\geq$ five years) - were collected through questionnaires. Smoking status was determined using the Fagerström Tolerance Questionnaire and classified as 'No' (individuals who do not smoke); and 'Yes' (for smokers, regardless of frequency). ${ }^{17}$ The Alcohol Use Disorders Identification Test (AUDIT) was used for assessment of alcohol consumption, that was classified as 'No' (individuals who do not drink); and 'Yes' (for those who drink, regardless of quantity or frequency)..$^{18}$

Anthropometric measurements of height and weight were collected with workers standing and wearing light clothing. Waist Circumference (WC) was measured in duplicate at the midpoint between the iliac crest and the lowest rib. WC greater than or equal to $90 \mathrm{~cm}$ were classified as central obesity. ${ }^{19}$ In addition, body mass index (BMI) and waist-to-height ratio (WHR) were analyzed. BMI was calculated by dividing body weight $(\mathrm{Kg})$ by the square of the height $(\mathrm{m})$, and classified according to the WHO criteria. ${ }^{20}$ The WHR was calculated by dividing WC by height. WHR values between 0.51 and 0.57 were classified as moderate risk, and values greater than or equal to 0.57 were classified as high risk. ${ }^{21}$

Body composition was assessed by percentage of body fat $(\mathrm{BF})$, which was estimated by bioelectrical impedance analysis, using a portable, tetrapolar monitor. Workers with BF greater than $25 \%$ were considered obese. ${ }^{22}$ Blood pressure (BP) was measured with the subject seated 
after a five-minute rest period in a calm environment, in triplicate, with a minimum interval of three minutes between measurements, using a MICROLIFE R digital semiautomatic device. Mineworkers with elevated BP were those with systolic blood pressure (SBP) greater than or equal to $130 \mathrm{mmHg}$ or diastolic blood pressure (DBP) greater than or equal to $85 \mathrm{mmHg} .{ }^{19}$

For biochemical variables, after fasting for 12 hours, $14 \mathrm{~mL}$ of venous blood were collected by vacuum puncture from the cubital vein into two tubes, one containing sodium fluoride to measure serum glucose, and another without anticoagulant to determine total cholesterol (TC), triglycerides (TG) and fractions (high-density lipoprotein [HDL], low-density lipoprotein [LDL]). Glucose levels above $100 \mathrm{mg} / \mathrm{dL}$ were considered elevated, ${ }^{19}$ and TG, TC, HDL-C, and LDL-C levels were classified according to the Brazilian Cardiology Society guidelines. ${ }^{23}$ The presence of Metabolic Syndrome (MS) was classified according to the International Diabetes Federation (IDF). ${ }^{19}$

Finally, the risk of developing CVD in 10 years was estimated through Global Risk Score, and classified as low risk $(<5 \%)$; moderate risk ( $\geq 5 \%$ and $\leq 20 \%)$; and high risk $(>20 \%){ }^{24}$ This score is also suggested by the I Brazilian guidelines for cardiovascular prevention, ${ }^{25}$ and its update. ${ }^{2}$

\section{Data analysis}

The risk management steps proposed by ISO 31000 (2018) were used as a basis and adapted to the context of occupational health and objectives of this work. ${ }^{26}$ All the analysis and plots presented and discussed in this paper were produced using the R Programming language v3.5.1 (R Core Team, 2019) with the RStudio IDE v1.3.125, Microsoft Excel 2013, IBM SPSS Statistics 20 and Minitab 17. The Anderson-Darling test was employed to verify the normality of the data, and the Pearson's Test to verify the correlation between the variables. Continuous variables with normal distribution were described as mean \pm standard deviation. Non-normally distributed continuous variables were described as median and interquartile range. Also, categorical variables were described using absolute and relative frequencies. The Wilcoxon test and paired t-test were used to compare median and means values, respectively, between 2010 and 2015. To analyze the association between variables and cardiovascular risk, the binary logistic regression was used. The chi-square and U Mann-Whitney tests were also employed to analyze risk factors through age groups. For all tests used, the significance level considered was 0.05 .

\section{Context establishment}

First, a descriptive analysis of sociodemographic variables is presented. The prevalence of risk factors in the population was identified, and the progression of risk factors for CVD among workers between 2010 and 2015 was analyzed using the Wilcoxon test and the paired t-test.

\section{Risk assessment}

In the second stage, the cardiovascular risk of participants was analyzed by descriptive analysis and presented as quartiles, boxplot, and prevalence in each risk classification. Cardiovascular risk variation between 2010 and 2015 was analyzed using Wilcoxon test, and the risk factors were analyzed using the U Mann-Whitney test (for quantitative variables) and chi-square test (for qualitative variables). Using univariate binary logistic regression, the factors significantly associated with an increased cardiovascular risk in 2015 were identified. Then, with the significantly associated variables, a multivariate binary logistic regression was adjusted for age, alcohol intake, and smoking. Furthermore, individuals were classified into 2 groups according to their median age to identify if there is a need for interventions or monitoring focused on a specific group. The differences between these groups were analyzed using the U Mann-Whitney test, and significant associations between age and risk factors for CVD in 2015 were identified using the chi-square test. Finally, the model was developed based on the prevalence of risk factors, assessed in the "context establishment" step, and on the factors significantly associated with cardiovascular risk and age.

\section{Results}

\section{Context establishment}

The study group was composed mainly of married men $(76.4 \%)$, who had been working shifts for more than five years (77.0\%); most had completed high school (59.2\%), followed by technical level education (24.6\%). Regarding ethnicity, $35.6 \%$ were white, $34.6 \%$ were mulattos, and $24.1 \%$ were black. Mean age of respondents at baseline was $34.27 \pm 6.94$ years.

Table 1 shows the descriptive analysis of cardiovascular risk factors in 2010, 2012, and 2015. Levels of low-density 
Table 1 - Descriptive analysis of cardiovascular risk factors of 191 mining haul truck operators in Minas Gerais, Brazil, in 2010, 2012, and 2015

\begin{tabular}{|c|c|c|c|c|}
\hline & $2010(n=191)$ & $2012(n=191)$ & $2015(n=191)$ & P-value \\
\hline Weight (kg) & $81.2(72.4-89.7) \ddagger$ & $80.7(72.4-88.2) \ddagger$ & $82.8(74.4-90.2) \ddagger$ & $<0.001^{*}$ \\
\hline BMI $\left(\mathrm{kg} / \mathrm{m}^{2}\right)$ & $26.5(23.9-29.0) \ddagger$ & $26.2(23.9-28.8) \ddagger$ & $27.1(24.7-29.4) \ddagger$ & $<0.001^{*}$ \\
\hline $\mathrm{BF}(\%)$ & $22.3 \pm 5.7 \dagger$ & $25.2 \pm 10.3+$ & $22.5 \pm 5.4 \dagger$ & 0.623 \\
\hline $\mathrm{WC}(\mathrm{cm})$ & $91.6 \pm 10.7 \dagger$ & $91.5 \pm 9.4 \dagger$ & $94.5 \pm 9.3+$ & $0.005^{*}$ \\
\hline WHR & $0.53(0.49-0.56) \ddagger$ & $0.52(0.49-0.56) \ddagger$ & $0.54(0.51-0.57) \ddagger$ & $<0.001^{*}$ \\
\hline $\mathrm{SBP}(\mathrm{mmHg})$ & $128.9 \pm 16.0 \dagger$ & $132.2 \pm 12.3 \dagger$ & $135.1 \pm 13.3+$ & $<0.001^{*}$ \\
\hline $\mathrm{DBP}(\mathrm{mmHg})$ & $79.6 \pm 9.8+$ & $82.8 \pm 8.4 \dagger$ & $84.6 \pm 9.1+$ & $<0.001^{*}$ \\
\hline TC (mg/dL) & $188.8(164.6-225.0) \ddagger$ & $189.0(166.0-222.0) \ddagger$ & $201.8(179.6-233.2) \ddagger$ & $<0.001^{*}$ \\
\hline HDL-C (mg/dL) & $43.1 \pm 10.8+$ & $56.2 \pm 15.2 \dagger$ & $52.7 \pm 11.1 \dagger$ & $<0.001^{*}$ \\
\hline LDL-C (mg/dL) & $117.8(96.6-152.6) \ddagger$ & 105.5 (83.0-133.0)‡ & $115.4(89.8-135.2) \ddagger$ & $0.001^{*}$ \\
\hline TG (mg/dL) & $123.3(95.8-168.6) \ddagger$ & $139.0(96.0-189.0) \ddagger$ & $172.8(127.0-242.5) \ddagger$ & $<0.001^{*}$ \\
\hline BG (mg/dL) & $89.0(84.4-97.0) \ddagger$ & $85.0(82.0-92.0) \ddagger$ & $89.4(83.9-95.4) \ddagger$ & 0.901 \\
\hline \multicolumn{5}{|c|}{$\begin{array}{l}\text { * Wilcoxon test and paired t-test for comparison between } 2010 \text { and 2015; }+ \text { values presented as mean } \pm \text { standard deviation; } \neq \text { values presented as median } \\
\text { and interquartile range; BMI: body mass index; BF: body fat; WC: waist circumference; WHR: waist-to-height ratio; SBP: systolic blood pressure; DBP: } \\
\text { diastolic blood pressure; TC: total cholesterol; HDL-C: high density lipoprotein cholesterol; LDL-C: low density lipoprotein cholesterol; TG: triglycerides, } \\
\text { BG: blood glucose }\end{array}$} \\
\hline
\end{tabular}

lipoprotein cholesterol significantly decreased from 2010 to 2015 , and a statistically significant increase in the other risk factors, except BF and plasma glucose levels, was observed in the same period.

Table 2 shows the prevalence of cardiovascular risk factors in participants in 2010, 2012, and 2015. There was a significant increase in BMI, central obesity, TG, and TC from 2019 to 2015 (Table 2). In addition, note the increase in WHR and BP, with $71 \%$ of the workers exhibiting increased WHR in 2015, and 69\% of the workers with elevated BP at the end of follow-up.

\section{Risk assessment}

In 2010, the risk of developing cardiovascular diseases in 10 years ranged between $1 \%$ and $18.4 \%$; however, in 2015 , this variation increased to between $1.1 \%$ and $30 \%$. The boxplot in Figure 1 indicates the risk quartiles in 2010,2012 , and 2015. The third quartile in 2010 was $5.6 \%$, and in 2015, 6.7\%. Thus, the Wilcoxon test indicated a significant increase of the risk during the follow-up ( $p<$ $0.001)$. Analysis for determining who were in the third quartile in 2010 and 2015 elucidated that $37 \%$ of the workers in this quartile in 2015 were not in this risk group in 2010 . Moreover, $74 \%$ of the workers who belonged to this quartile in 2010 showed an increase in cardiovascular risk. Therefore, from 2010 to 2015, the workers acquired additional risk factors for CVD.

In the risk categories, an upward trend of moderate and high risks was observed. In 2010, 31.9\% of mineworkers were at moderate risk, and none was classified as high risk. In 2015, the prevalence of workers at moderate risk was $34.6 \%$ and the number of workers at high risk was $2.1 \%$. Meanwhile, the prevalence of low risk dropped from $68.1 \%$ in 2010 to $63.3 \%$ in 2015 .

Due to the increase in the number of individuals at moderate and high risks in 2015, we evaluated the risk factors at the end of the follow-up in these categories. For this analysis, individuals at moderate and high risks were gathered in the same group: Moderate/High. There was a significant difference in the factors: age, WHR, SBP, BG, HLD-C, and LDL-C between the risk classifications. The chi-square found a significant association between risk categories and the prevalence of smoking, alcohol intake, and MS (See Table S1 in Supplementary material). 
Table 2 - Prevalence of cardiovascular risk factors of 191 mining haul truck operators in Minas Gerais, Brazil, in 2010, 2012, and 2015

$\begin{array}{llllll}2010 & 2012 & 2015 & \% \text { Variation } & \% \text { Variation } & \text { \% Variation } \\ \text { N (\%) } & \text { N (\%) } & \text { N (\%) } & (2010-2012) & (2012-2015) & (2010-2015)\end{array}$

$$
\text { Alcohol intake }
$$

\begin{tabular}{ccccccc}
\hline No & $50(26)$ & $60(31)$ & $62(32)$ & 20 & 3 & -2 \\
\hline Yes & $141(74)$ & $131(69)$ & $129(68)$ & -7 & & -8 \\
\hline Smoking & & & & & 2 & 5 \\
\hline No & $156(82)$ & $161(84)$ & $164(86)$ & 3 & -10 & -23 \\
\hline Yes & $35(18)$ & $30(16)$ & $27(14)$ & -14 & &
\end{tabular}

\begin{tabular}{lcccccc}
\hline Underweight & $2(1.1)$ & $1(0.5)$ & $0(0.0)$ & -50 & a & -21 \\
\hline Normal & $61(31.9)$ & $67(35.1)$ & $53(27.8)$ & 10 & 8 & -13 \\
\hline Overweight & $92(48.2)$ & $91(47.6)$ & $98(51.3)$ & -1 & 25 & 6 \\
\hline Obese & $36(18.9)$ & $32(16.8)$ & $40(20.9)$ & -11 & 11 \\
\hline
\end{tabular}

\begin{tabular}{|c|c|c|c|c|c|c|}
\hline \multicolumn{7}{|l|}{$\mathrm{BF}$} \\
\hline Normal & $132(70)$ & $114(60)$ & $123(65)$ & -14 & 8 & -7 \\
\hline Obese & $58(30)$ & $75(40)$ & $66(35)$ & 29 & -12 & 14 \\
\hline \multicolumn{7}{|l|}{ WC } \\
\hline Normal & $85(44)$ & $82(43)$ & $53(28)$ & -4 & -35 & -38 \\
\hline Central obesity & $106(56)$ & $109(57)$ & $138(72)$ & 3 & 27 & 30 \\
\hline \multicolumn{7}{|l|}{ WHR } \\
\hline Good & $78(41)$ & $86(45)$ & $55(29)$ & 10 & -36 & -30 \\
\hline Regular & $73(38)$ & $68(36)$ & $82(43)$ & -7 & 21 & 12 \\
\hline Bad & $40(21)$ & $37(19)$ & $54(28)$ & -7 & 46 & 35 \\
\hline \multicolumn{7}{|l|}{ BP } \\
\hline Normal & $92(48)$ & $80(42)$ & $59(31)$ & -13 & -26 & -36 \\
\hline Raised BP & $99(52)$ & $111(58)$ & $132(69)$ & 12 & 19 & 33 \\
\hline \multicolumn{7}{|l|}{ MS } \\
\hline No & $138(72)$ & $133(70)$ & $115(60)$ & -4 & -14 & -17 \\
\hline Yes & $53(28)$ & $58(30)$ & $76(40)$ & 9 & 31 & 43 \\
\hline \multicolumn{7}{|l|}{ TC } \\
\hline$<190 \mathrm{mg} / \mathrm{dL}$ & $97(51)$ & $98(51)$ & $68(36)$ & 1 & -31 & -30 \\
\hline$\geq 190 \mathrm{mg} / \mathrm{dL}$ & $94(49)$ & $93(49)$ & $123(64)$ & -1 & 32 & 31 \\
\hline \multicolumn{7}{|l|}{ HDL-C } \\
\hline$>40 \mathrm{mg} / \mathrm{dL}$ & $118(62)$ & $162(85)$ & $170(89)$ & 37 & 5 & 44 \\
\hline$\leq 40 \mathrm{mg} / \mathrm{dL}$ & $73(38)$ & $29(15)$ & $21(11)$ & -60 & -28 & -71 \\
\hline \multicolumn{7}{|l|}{ LDL-C } \\
\hline$<160 \mathrm{mg} / \mathrm{dL}$ & $154(81)$ & $173(91)$ & $163(89)$ & 12 & -2 & 6 \\
\hline$\geq 160 \mathrm{mg} / \mathrm{dL}$ & $37(19)$ & 18 (9) & $20(11)$ & -51 & 16 & -46 \\
\hline
\end{tabular}




\begin{tabular}{|c|c|c|c|c|c|c|}
\hline \multicolumn{7}{|l|}{ TG } \\
\hline$<150 \mathrm{mg} / \mathrm{dL}$ & $129(68)$ & $105(55)$ & $74(39)$ & -19 & -30 & -43 \\
\hline$\geq 150 \mathrm{mg} / \mathrm{dL}$ & $62(32)$ & $86(45)$ & $117(61)$ & 39 & 36 & 89 \\
\hline \multicolumn{7}{|l|}{ BG } \\
\hline$<100 \mathrm{mg} / \mathrm{dL}$ & $158(83)$ & $170(91)$ & $171(90)$ & 10 & -2 & 8 \\
\hline$\geq 100 \mathrm{mg} / \mathrm{dL}$ & $33(17)$ & $17(9)$ & $20(10)$ & -47 & 15 & -39 \\
\hline
\end{tabular}

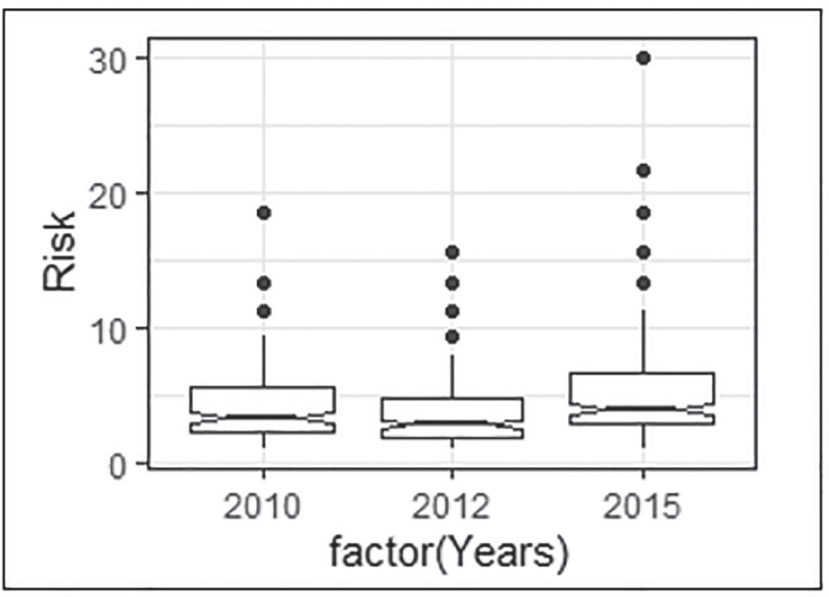

Figure 1 - Boxplot of cardiovascular risk of 191 haul truck operators of a mining company in Minas Gerais, Brazil, in 2010,2012 and 2015

In addition, a univariate analysis was carried out through binary logistic regression. The variables age and SBP showed a statistically significant relationship with the risk classification. A one-year increase in age and an increase of $1 \mathrm{mmHg}$ in SBP resulted in a $47 \%$ and a $2.8 \%$ increase, respectively, in the odds of the worker belonging to the moderate/high risk group. The HDL-C, LDL-C, and BG also exhibited significant association with cardiovascular risk. A one $\mathrm{mg} / \mathrm{dL}$ increase in HDL-C reduced the chance of the worker being at moderate/high risk by $3.2 \%$. This same increase in LDL-C and BG increased the odds of the worker belonging to the moderate/high group by $1.1 \%$ and $4.8 \%$, respectively. This same significant relationship was found for the categorical variables MS, alcohol intake, and smoking. The presence of MS, alcohol intake and smoking increased the odds of a worker being at a higher risk by $95.1 \%$, in two times and 14 times, respectively (See Table S2 in Supplementary material).

A multivariate binary logistic regression was adjusted, using the significant risk factors. Table 3 elucidates that, after adjusting for age, alcohol intake, and smoking, the variables SBP, HDL-C, and LDL-C still had significant association with cardiovascular risk. An increase of $1 \mathrm{mmHg}$ in SBP increased by $14.6 \%$ a worker's chance of belonging to Moderate/ High risk. Furthermore, an increase of $1 \mathrm{mg} / \mathrm{dL}$ in HDL-C reduced the chance of a mineworker being at moderate/high risk by $15.8 \%$. This same increase in LDL-C raised by $5.1 \%$ the chance of the worker belonging to this group.

In addition, the association between age and the significant risk factors in 2015 was analyzed to verify whether closer monitoring of a particular group 
Table 3 - Binary logistic regression adjusted for the risk factors that showed a statistically significant relationship with the risk classification in the multivariate analysis of data from 191 mining haul truck operators in Minas Gerais, Brazil in 2015

\begin{tabular}{lccccc}
\hline Risk factors & $\beta$ & Standard Error & Odds ratio & 95\% Confidence interval & P-value \\
\hline SBP & 0.136 & 0.041 & 1.146 & $(1.058 ; 1.241)$ & $0.001^{*}$ \\
\hline HDL-C & -0.172 & 0.050 & 0.842 & $(0.763 ; 0.928)$ & $0.001^{*}$ \\
\hline LDL-C & 0.050 & 0.015 & 1.051 & $(1.020 ; 1.083)$ & $0.001^{*}$ \\
\hline BG & -0.041 & 0.043 & 0.960 & $(0.882 ; 1.045)$ & 0.349 \\
\hline MS & 0.595 & 0.768 & 1.814 & $(0.403 ; 8.170)$ & 0.438 \\
\hline $\begin{array}{l}\text { Adjusted model for age, alcohol intake, and smoking. Due to the nature of the data, the variable waist-to-hip ratio was not considered. }{ }^{*} P \text {-value< } 0.05 ; \text { SBP: } \\
\text { systolic blood pressure; HDL-C: high-density lipoprotein cholesterol; LDL-C: low-density lipoprotein cholesterol; BG: Blood Glucose; MS: Metabolic syndrome. }\end{array}$ \\
\hline
\end{tabular}

was needed. Using the chi-square test, a significant association was found between age and blood glucose $(\mathrm{p}$-value $=0.015)$, smoking $(\mathrm{p}$-value $=0.004)$, and alcohol intake $(\mathrm{p}$-value $=0.040)$.

With these analyses, a model (Figure 2) was developed to assist the decision-making for CVD risk management in this population. Interventions should target risk factors that are highly prevalent in this population, to cover a larger number of workers.

Finally, a retrospective risk analysis was performed, analyzing the model from a longitudinal perspective, for the same group of workers. Thus, the variables MS and SBP in 2010 and the variables BG and SBP in 2012 remained in the same quadrant. In addition, despite not belonging to the same quadrant, the variables HDL-C and smoking were also present in the model in 2010. The same occurred with the risk factors WHR, smoking, and MS in 2012.

\section{Discussion}

Many studies on risk factors for CVD have been

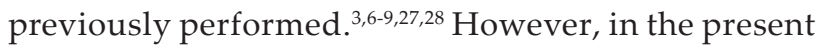
study, these risk factors were used to develop a model to assist in decision making in CVD risk management in a team of haul truck operators of a mining company in Brazil. The workers operate at the beginning of the mining process and are responsible for the daily transport of tons of a commodity used worldwide. Additionally, they operate in a sector responsible for an important share of GDP in Brazil and for generating a considerable number of jobs in the country. Furthermore, the mining sector is present in several locations around the world, so we believe that our study offers an insight into the management of cardiovascular risk that may be reproduced in other countries. In addition, this work contributes to the expansion of literature about cardiovascular risk management in an occupational context through a longitudinal study. The course of the cardiovascular risk factors was monitored in three phases - 2010, 2012, and 2015.

Due to the increase of CVD risk during the follow-up, the factors associated with moderate and high risks in 2015 were analyzed. Many factors are known to increase the risk of developing CVD. ${ }^{1,2}$ The proposed model indicated which of these factors are associated with an increased cardiovascular risk in this population. This allows for more effective and efficient prevention actions because investments can be aimed at reducing or eliminating the most serious risk factors for the health of these workers.

Of the 17 factors analyzed, only eight modifiable factors were associated with a higher cardiovascular risk in this population. In addition, some factors (alcohol intake, raised $\mathrm{BP}$, and inadequate WHR), due to their higher prevalence, require more investments through more intense interventions. The results also indicated that interventions aimed at reducing some risk factors (alcohol intake, smoking, and raised BG) must be differentiated according to the age of the individuals.

The WHR of the mineworkers in 2015 were higher than those found in a study conducted with shift workers in Brazil. ${ }^{8}$ The associations identified between risk and SBP, smoking, ${ }^{27}$ alcohol intake, LDL-C, BG, ${ }^{28}$ and the presence of $\mathrm{MS},{ }^{6}$ are in line with some studies in literature. However, the prevalence of arterial 


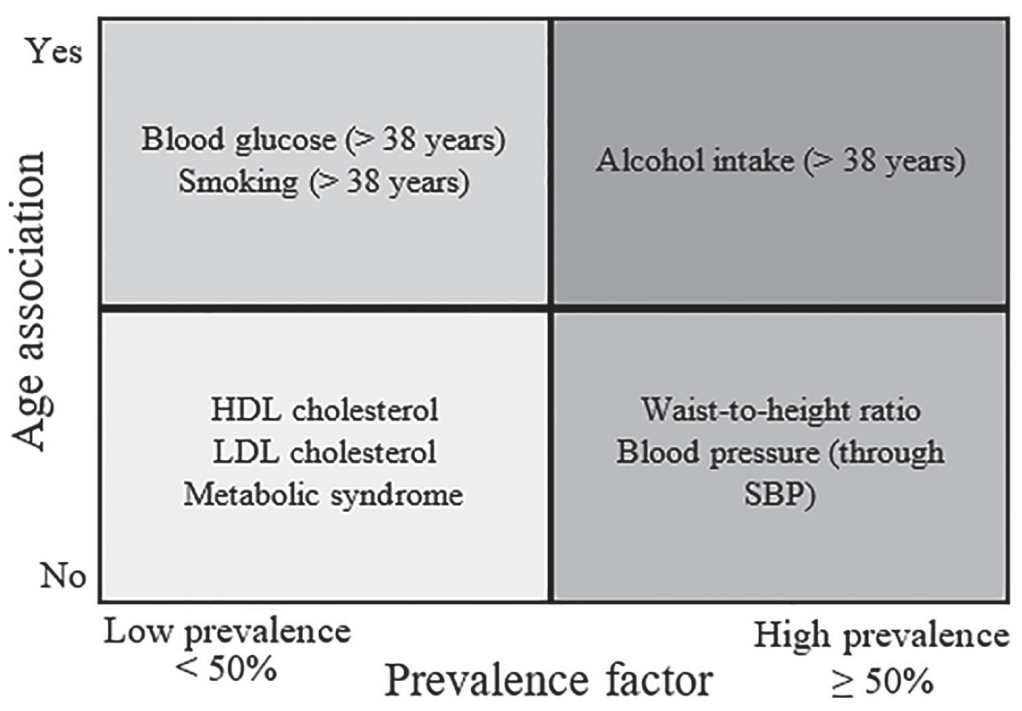

Figure 2 - Model to aid cardiovascular risk management developed from data of 191 haul truck operators of a mining company in Minas Gerais, Brazil; HDL: high-density lipoprotein; LDL: low-density lipoprotein; SBP: systolic blood pressure

hypertension and alcohol intake in the study group was much higher than those found in a general population living in middle-income countries, including Brazil. ${ }^{3}$ Finally, some studies indicate an association between shift work and CVD or its risk factors, ${ }^{8,9}$ but this study found no significant association between time of shift work and cardiovascular risk.

This study has some limitations. The model presented took into account data from haul truck operators in the mining sector. Therefore, care must be taken when generalizing the results to another population of workers. In this sense, future research may create models to assist the management of cardiovascular risk in other sectors and group of workers. The analysis of some risk factors for CVD according to the WHO, such as physical inactivity and diet was not part of the scope of this work, and thus, future research may consider these factors. Finally, this study evaluated only the time of shift work as an occupational factor, and factors such as long working hours and stress at work have already been presented as possible aggravating factors of cardiovascular risk. Therefore, future models to aid in cardiovascular risk management may consider these occupational factors.

\section{Conclusions}

The factors associated with greater cardiovascular risk in these workers were high LDL cholesterol, reduced HDL cholesterol, and the presence of MS. Smoking, alcohol consumption, and high glucose levels also contributed to a higher risk and were more prevalent in workers over 38 years of age. Inadequate WHR, alcohol consumption, and high blood pressure were associated with high risk and were highly prevalent in the population studied. From a longitudinal perspective, the variables MS and SBP in 2010 and the variables glucose and SBP in 2012 remained in the same quadrant. Despite not belonging to the same quadrant, the variables HDL-C, WHR, and smoking were present in the model in at least one of the other two years of follow-up. Therefore, interventions in the mining sector should focus on improving these risk factors, with participation and engagement of workers and leaders.

\section{Author contributions}

Conception and design of the research: Marques RAM, Nascimento Neto RM, Silva AL, Oliveira FLP. Acquisition of data: Camargo PP, Fajardo VC. Analysis and interpretation of the data: Marques RAM, Camargo PP, Fajardo VC, Oliveira FLP. Statistical analysis: Marques RAM, Camargo PP, Oliveira FLP. Obtaining financing: Nascimento Neto RM. Writing of the manuscript: Marques RAM. Critical revision of the manuscript for intellectual content: Gouvea 
GDR, Souza GGL, Silva AL. General coordinator of the project: Nascimento Neto RM. Research project supervisor: Silva AL, Oliveira FLP.

\section{Potential Conflict of Interest}

No potential conflict of interest relevant to this article was reported.

\section{Sources of Funding}

This study was partially funded by CNPq (grant number 306441/2019-5); FAPEMIG (grant number PPM-00321-18). Universidade Federal de Ouro Preto (grant number 1325).

\section{References}

1. World Health Organization.(WHO). Cardiovascular diseases (CVDs);2017. [Internet]. [cited 2019 Nov 19]. Available from: https:// www.who.int/news-room/fact-sheets/detail/cardiovascular-diseases(cvds).

2. Précoma DB, de Oliveira GMM, Simão AF, Dutra OP, Coelho OR, Izar MCO, et al. Atualização da Diretriz de Prevenção Cardiovascular da Sociedade Brasileira de Cardiologia . Arq Bras Cardiol. 2019;113(4):787-891. doi:10.5935/abc.20190204.

3. Yusuf S, Joseph P, Rangarajan S, Islam S, Mente A, Hystad P, et al. Modifiable risk factors, cardiovascular disease, and mortality in 155722 individuals from 21 high-income, middle-income, and low-income countries (PURE): a prospective cohort study. Lancet. 2020;395(10226):795-808. doi:10.1016/S0140-6736(19)32008-2.

4. Instituto Brasileiro de Geografia e Estatística. (IBGE). Tabelas Completas do Sistema de Contas Nacionais Trimestrais. 2019. [Internet]. [cited 2020 May 7]. Available from: https://www.ibge.gov. br/estatisticas/economicas/contas-nacionais/9300-contas-nacionaistrimestrais.html?=\&t=resultados

5. Instituto Brasileiro de Mineração (IBRAM). Economia Mineral. 2019. [Internet] [cited 2020 May 10]. Available from: http:// portaldamineracao.com.br/wp-content/uploads/2019/07/numerosjun2019.pdf

6. Chen WL, Wang CC, Chiang ST, Wang YC, Sun YS, Wu W Te, et al The impact of occupational psychological hazards and metabolic syndrome on the 8-year risk of cardiovascular diseases-A longitudinal study. PLoS One. 2018;13(8):e0202977. doi: 10.1371/ journal.pone.0202977.

7. Kivimäki M, Kawachi I. Work Stress as a Risk Factor for Cardiovascular Disease. Curr Cardiol Rep. 2015;17(9):630. doi:10.1007/s11886-0150630-8.

8. Souza BB, Monteze NM, Luiz F, Oliveira P De, Oliveira JM De, Freitas SN De, et al. Lifetime shift work exposure : association with anthropometry, body composition, blood pressure, glucose and heart rate variability. Occup Environ Med. 2015;72(3):208-15. doi: 10.1136/oemed-2014-102429.

9. Wang D, Ruan W, Chen Z, Peng Y, Li W. Shift work and risk of cardiovascular disease morbidity and mortality: A dose-response meta-analysis of cohort studies. Eur J Prev Cardiol. 2018;25(12):1293302. doi: $10.1177 / 2047487318783892$.

10. da Silva SLC, Amaral FG. Critical factors of success and barriers to the implementation of occupational health and safety management systems: A systematic review of literature. Saf Sci. 2019;117:123-32.

\section{Study Association}

This article is part of the thesis of master submitted by Rafaela Aparecida Mendonça Marques, from Universidade Federal de Ouro Preto.

\section{Ethics approval and consent to participate}

This study was approved by the Ethics Committee of the Universidade Federal de Ouro Preto under the protocol number CAAE: 0018.0.238.000-11 and CAAE: 39682014.7.0000.5150. All the procedures in this study were in accordance with the 1975 Helsinki Declaration, updated in 2013. Informed consent was obtained from all participants included in the study.

11. Perk J, De Backer G, Gohlke H, Graham I, Reiner Ž, Verschuren WMM, et al. European Guidelines on cardiovascular disease prevention in clinical practice (version 2012). The Fifth Joint Task Force of the European Society of Cardiology and Other Societies on Cardiovascular Disease Prevention in Clinical Practice (constituted by re. Atherosclerosis. 2012;223(1):1-68. doi:10.1016/j. atherosclerosis.2012.05.007.

12. Momtazi-Borojeni AA, Banach M, Reiner Ž, Pirro M, Bianconi V, Al-Rasadi $\mathrm{K}$, et al. Interaction Between Coronavirus S-Protein and Human ACE2: Hints for Exploring Efficient Therapeutic Targets to Treat COVID-19. Angiology. 2021;72(2):122-30. doi:10.1177/0003319720952284.

13. Reiner Ž, Hatamipour M, Banach M, Pirro M, Al-Rasadi K, Jamialahmadi T, et al. Statins and the Covid-19 main protease: In silico evidence on direct interaction. Arch Med Sci. 2020;16(2):490-6. doi: 10.5114 /aoms.2020.94655

14. Wang B, Li R, Lu Z, Huang Y. Does comorbidity increase the risk of patients with covid-19: Evidence from meta-analysis. Aging (Albany NY). 2020;12(7):6049-57. doi: 10.18632/aging.103000.

15. Zheng Z, Peng F, Xu B, Zhao J, Liu H, Peng J, et al. Risk factors of critical \& mortal COVID-19 cases: A systematic literature review and meta-analysis. J Infect. 2020;12(7):6049-57. doi:10.1016/j. jinf.2020.04.021.

16. Kassir R. Risk of COVID-19 for patients with obesity. Obes Rev. 2020;21(6):10-1.

17. Sociedade Brasileira de Pneumologia e Tisiologia (SBPT). Diretrizes clínicas na saúde suplementar-tabagismo. Rev Assoc Med Bras. 2011;56(4):375-93

18. Babor TF, Higgins-Biddle JC, Saunders JB, Monteiro MG. The alcohol use disorders identification test (AUDIT): Guidelines for use in primary care. 2nd ed. Geneva: WHO; 2001. 1-37 p

19. International Diabetes Federation (IDF). The IDF consensus worldwide definition of the metabolic syndrome. International Diabetes Federation. IDF Communications; 2006.

20. World Health Organization. (WHO). What is overweight and obesity? [Internet]. [cited 2020 Mar 20]. Available from: https://www.who.int/ dietphysicalactivity/childhood_what/en/

21. Sociedade de Cardiologia do Estado do Rio de Janeiro (SOCERJ) Manual de Prevenção Cardiovascular.2017. [Internet]. [cited 2019 Sep 5]. Available from: https://socerj.org.br/antigo/wp-content/ uploads//2017/05/Manual_de_Prevencao_Cardiovascular_SOCERJ.pdf 
22. US Department of Health and Human Services. Understanding Adult Obesity.2008. [Internet]. [cited 2020 Feb 18]. Available from: http:// win.niddk.nih.gov/publications/PDFs/adultobesbw1201.pdf

23. Faludi AA, Izar MCO, Saraiva JFK, Chacra APM, Bianco HT, Afiune Neto A, et al. Atualização da Diretriz Brasileira de Dislipidemias e Prevenção da Aterosclerose. Arq Bras Cardiol. 2017;109(2):1-76. doi: 10.5935/abc. 20170121.

24. Xavier HT, Izar M, Faria Neto JR, Asaad MH, Rocha VZ, Sposito AC, et al. V Brazilian Guidelines of dyslipidemias prevention of atherosclerosis. Arq Bras Cardiol. 2013;101(4) Suppl):1-22. doi:10.5935/abc.2013S010.

25. Simão AF, Precoma DB, Andrade JP, Correa Filho H, Saraiva JFK, GMM Oliveira, et al. I Diretriz Brasileira de Prevenção
Cardiovascular. Arq Bras Cardiol. 2013;101(6):1-63. doi: 10.5935/ abc.2013S012.

26. International Organization for Standardization. (ISO) 31000: Risk management: Guidelines. International Organization for Standardization; 2018.

27. Guerra-Silva NMM, Santucci FS, Moreira RC, Massao Tashima C, de Melo SCCS, Pereira LRL, et al. Coronary disease risk assessment in men: Comparison between ASCVD Risk versus Framingham. Int J Cardiol. 2017;228:481-7. doi: 10.1016/j.ijcard.2016.11.102.

28. Elshatarat RA, Burgel BJ. Cardiovascular Risk Factors of Taxi Drivers. J Urban Health. 2016;93(3):589-606. doi:10.1007/s11524-016-0045-x.

\section{*Supplemental Materials}

For additional information, please click here. 